\title{
Design and Implementation of an Automotive BLDC Motor for a Continuous Variable Valve Lift System
}

\author{
Soo-Whang Baek \\ Department of Automotive Engineering, Honam University, Korea \\ swbaek@honam.ac.kr
}

\begin{abstract}
Various studies have been carried out to improve the fuel economy and power of automobile engines. They have shown that the valve train that regulates the intake and exhaust of the engine has a great influence on fuel consumption and vehicle output. To this end, the continuous variable valve lift system (CVVL), also called the continuous variable valve lift, has been developed. Conventional CVVL systems use direct current $(D C)$ motors to control intake valves; however, BLDC-type motors are currently being developed to improve the durability and performance of automobile engines. The purpose of this study was to implement a CVVL system using BLDC motors. The torque value delivered to the intake shaft was measured experimentally to obtain the torque of the motor required to smoothly drive the CVVL system. Based on this, a BLDC motor was designed and a controller for driving the BLDC motor was implemented. Finally, we confirmed the suitability of the designed BLDC motor by applying it to the CVVL system.
\end{abstract}

Keywords: BLDC, Motor, Automotive, Continuous, Variable, Valve, Lift

\section{Introduction}

In recent years, environmentally friendly and fuel-efficient technologies for low-carbon green growth have been actively pursued in accordance with international environmental regulations, such as Euro 6, which is a vehicle emission regulation [1,2]. Research on the development of new power sources, such as hybrid vehicles and technologies, to improve the efficiency of existing internal combustion engines is actively underway [3]. In addition, $\mathrm{CO}_{2}$ regulations continue to strengthen in response to global warming. To meet the continuous demands for improvement of the performance of the vehicle, there is a need for a technique that optimizes the control of the intake and exhaust valves, which are directly related to the performance and fuel consumption of the engine, in all the operation regions of the engine [4]. In response to these technological trends, a new technology called powertrain technology is under research and development to improve the fuel efficiency of automobiles. A variable intake system (VIS) has been developed that improves the fuel efficiency of the intake of the engine and improves the fuel economy and the output of the engine by changing the length or cross-sectional area of the intake manifold [5]. Furthermore, studies have been conducted on variable valve timing (VVT), which regulates the cylinder charge amount and the residual gas amount by controlling the timing of valve opening and closing, and the valve overlap according to the operation region $[6,7]$. Recently, a continuous variable valve timing (CVVT) system for an intake valve that continuously controls valve timing in the entire operation region has become popular [8-10]. However, even when the valve timing is adjusted differently at low speeds, if the lift of the intake valve is not made small, the flow velocity of the intake air becomes low, so that it is difficult to increase the volume efficiency, and the combustion becomes unstable. Accordingly, there is a need for a technique for performing

Received (July 16, 2018), Review Result (September 10, 2018), Accepted (September 18, 2018) 
valve lift control in combination with valve timing control according to the operation region. Applying a continuous variable valve lift (CVVL) system that continuously controls the valve lift over the entire operating range of the vehicle engine can further improve engine performance and maximize fuel economy improvement [11-14]. In the CVVL system, intake air control is possible in the entire engine speed range, so that the intake control function of the throttle valve is not required. In the CVVL system, the intake valve, rather than the throttle body, adjusts the intake air amount, thereby reducing the pumping loss, improving the full load performance at low speed, and improving the fuel efficiency of the vehicle by about 5\%. Most of the existing CVVL system technologies employ direct current (DC) motors. DC motors have the disadvantage of poor control accuracy and poor durability. Therefore, the research and development of a CVVL system that applies the BLDC motor with relatively high performance is underway. In this study, we investigated the design and implementation of an automotive BLDC motor for a CVVL system. The BLDC motor was designed to improve the control precision and durability of the CVVL system. The torque required to control the CVVL shaft was experimentally measured and reflected in the BLDC motor design. The characteristics of the BLDC motor were verified by two dimensional (2D) finite element analysis, and the controller was implemented to drive the motor. Finally, the BLDC motor was attached to the CVVL engine assembly to verify performance.

\section{Structure of CVVL Engine Assembly}

Figure 1 shows the components of the CVVL engine assembly. The CVVL engine assembly consists of a CVVL shaft, worm gear, and BLDC motor for controlling the intake valve lift to a common gasoline engine. In the four-stroke gasoline engine, the function of the intake and exhaust valves is to control the flow of intake and exhaust air in the cylinder, and to maintain air-tightness in the cylinder. During the compression stroke and the explosion stroke, both the intake and exhaust valves are closed to maintain air-tightness in the cylinder. During the intake stroke and the exhaust stroke, only the intake valve or the exhaust valve is opened to suck the airfuel mixture and discharge the combustion gas. However, in most cases, only intake valve control is controlled owing to cost. The opening and closing of the intake valve is performed by the cam located at the camshaft pushing the end of the valve by the rocker arm against the CVVL shaft and the camshaft rotates by receiving the driving force of the crankshaft by the timing chain. Valve lift is an important factor determining the air-tightness of the valve and the amount of intake and exhaust gas. The valve lift is a measure of how far the valve face is from the valve seat. In the case of an intake valve, the larger the valve lift, the greater the amount of fuel gas flowing into the cylinder upon inhalation. In the case of the exhaust valve, the larger the valve lift, the greater the amount of combustion gas exhausted during the exhaust, thereby increasing the intake and exhaust efficiency.

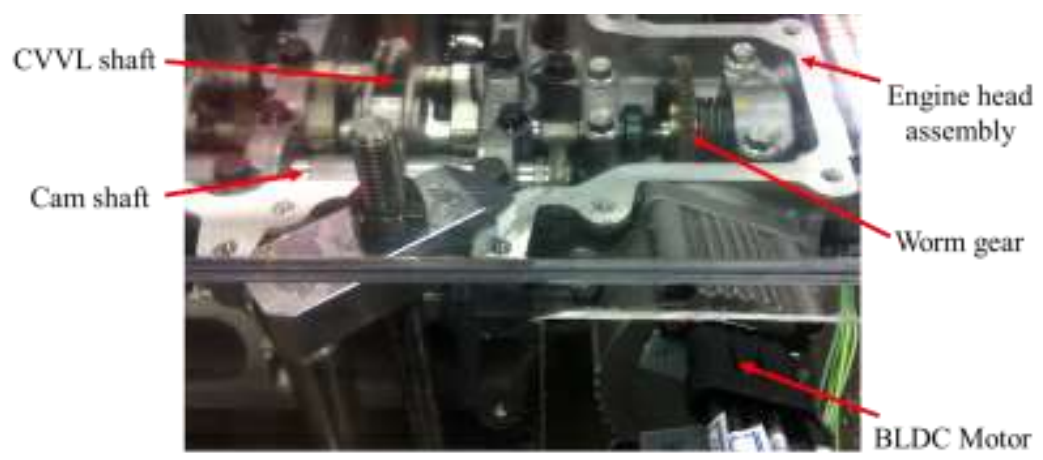

Figure 1. CVVL Engine Assembly 


\section{Measurement of CVVL Shaft Torque}

Figure 2 shows the configuration for CVVL shaft torque measurement. To express the rotational speed of the engine, the intake shaft of the CVVL engine head assembly is connected to the drive motor, and its rotational speed is equal to the rotational speed of the crankshaft. The intake shaft is connected to the torque sensor, and the torque sensor transmits the respective torque values generated according to the rotation speed of the drive motor to the measuring instrument and the oscilloscope. The torque of the intake shaft is similar to the torque transmitted from the CVVL shaft through a worm gear with a gear ratio of 60:1 to the BLDC motor. To select the specifications of the BLDC motor to drive the CVVL system, one needs to know the torque value that acts on the load of the CVVL shaft. Therefore, an experiment was performed based on the test configuration in Figure 2, and the torque of the camshaft was measured.

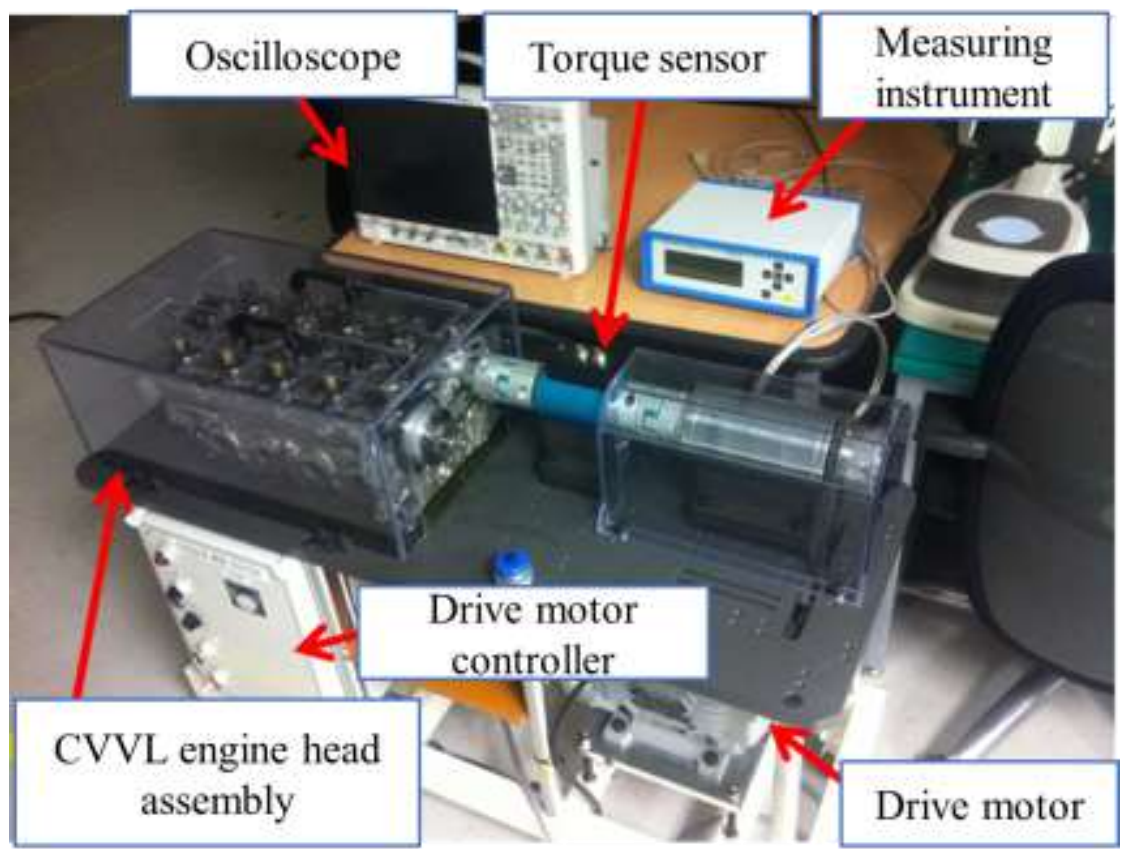

Figure 2. Configuration for Camshaft Torque Measurement

Figure 3 shows the experimental values of the waveforms of the camshaft torque. For the experiment, the rotational speed conditions of the crankshaft were $50 \mathrm{rpm}$, $500 \mathrm{rpm}$, and $1000 \mathrm{rpm}$. The experiment was carried out to measure the torque according to the rotational speed change in the camshaft of the CVVL engine head assembly. The experiments show that the torque required to control the valve lift is higher than the high rpm at low rpm. Table 1 shows the maximum torque (Tmax), minimum torque (Tmin), torque ripple (Tpp), and average torque (Tavg) of the camshaft under crankshaft rotational speeds of $50 \mathrm{rpm}$ to $1000 \mathrm{rpm}$. The torque of the BLDC motor, which is larger than the maximum value of the Tpp of the camshaft, is required for stable variable valve lifting even at low speeds. The actual torque of the camshaft of the CVVL engine should be multiplied by 60 times the torque characteristic shown in Figure 3 considering the reduction ratio of the worm gear. Therefore, the rated torque and output of the BLDC motor for the CVVL system were set to $0.35 \mathrm{Nm}$ and $120 \mathrm{~W}$, respectively. 


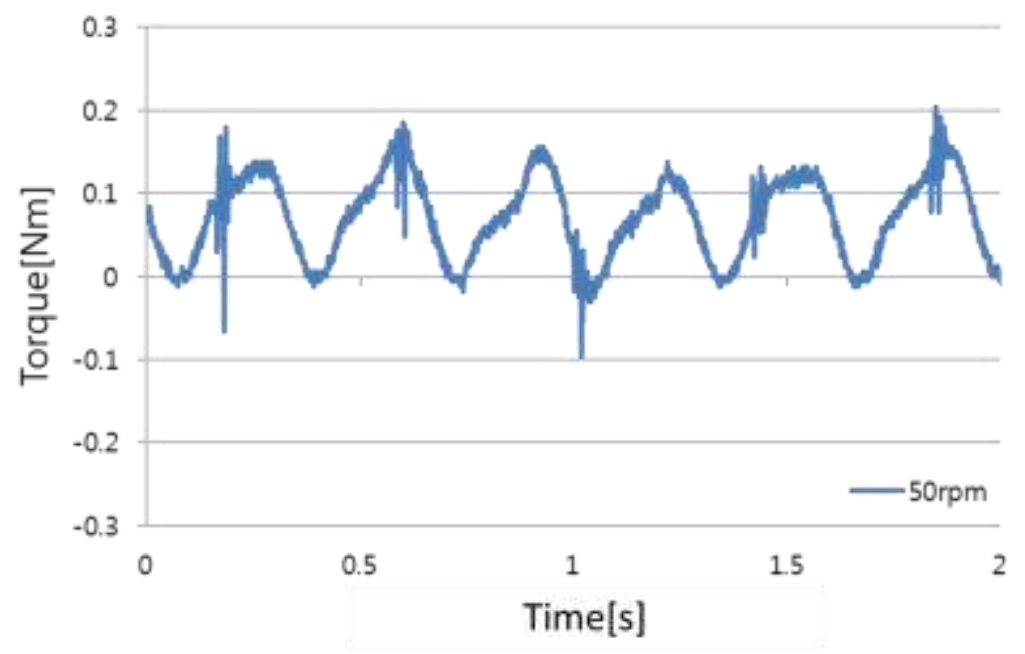

(a) $50 \mathrm{rpm}$

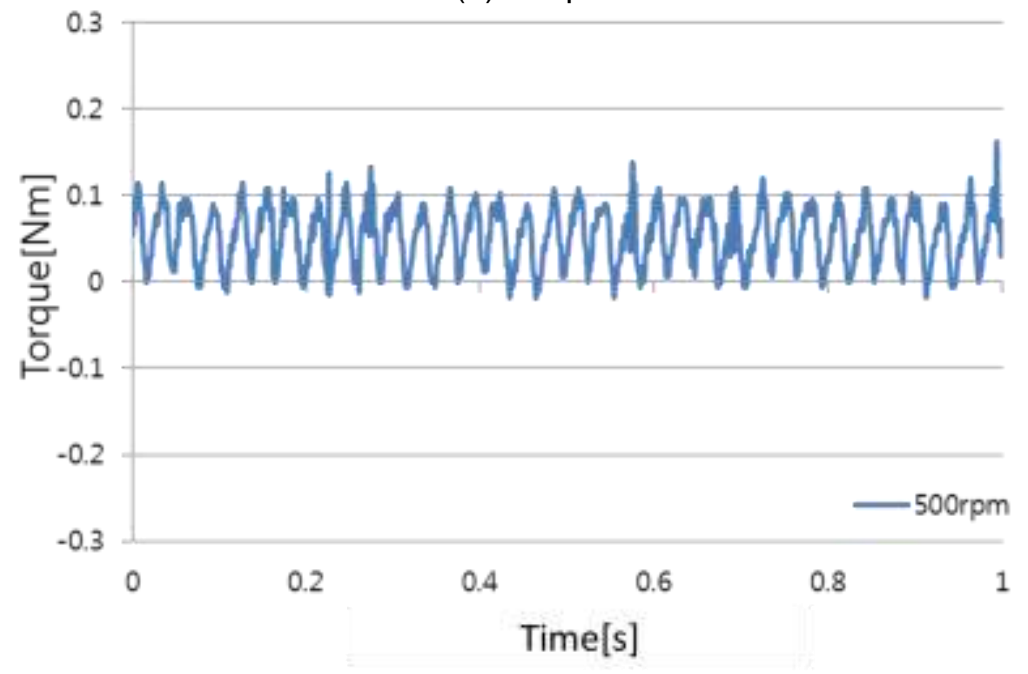

(b) $500 \mathrm{rpm}$

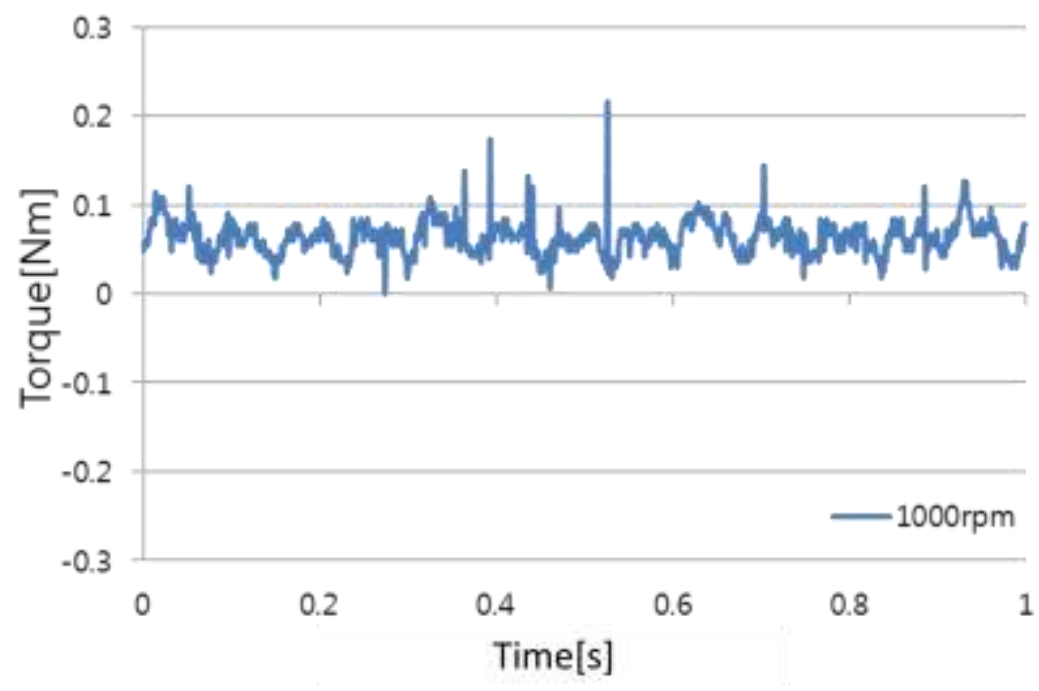

(c) $1000 \mathrm{rpm}$

Figure 3. Waveforms of Camshaft Torque 
Table 1. Torque Characteristics of the Camshaft

\begin{tabular}{|c|c|c|c|c|}
\hline Speed[rpm] & Tmax $[\mathbf{N m}]$ & Tmin[Nm] & Tpp[Nm] & Tavg[Nm] \\
\hline $\mathbf{5 0}$ & 0.252 & -0.096 & 0.348 & 0.0695 \\
\hline $\mathbf{1 0 0}$ & 0.246 & -0.084 & 0.33 & 0.0195 \\
\hline $\mathbf{2 0 0}$ & 0.246 & -0.062 & 0.308 & 0.0191 \\
\hline $\mathbf{3 0 0}$ & 0.252 & -0.06 & 0.312 & 0.0473 \\
\hline $\mathbf{4 0 0}$ & 0.15 & -0.09 & 0.24 & 0.0500 \\
\hline $\mathbf{5 0 0}$ & 0.162 & -0.018 & 0.18 & 0.0533 \\
\hline $\mathbf{6 0 0}$ & 0.186 & -0.054 & 0.24 & 0.0547 \\
\hline $\mathbf{7 0 0}$ & 0.12 & -0.048 & 0.168 & 0.0562 \\
\hline $\mathbf{8 0 0}$ & 0.162 & -0.024 & 0.186 & 0.0604 \\
\hline $\mathbf{9 0 0}$ & 0.168 & -0.096 & 0.264 & 0.0614 \\
\hline $\mathbf{1 0 0 0}$ & 0.216 & -0.002 & 0.218 & 0.0631 \\
\hline
\end{tabular}

Figure 4 shows the torque ripple (Tpp) of the camshaft; the values are based on those listed in Table 1. The torque ripple generated according to the speed of the camshaft shows a tendency to decrease gradually at high speeds. In fact, the engine speed condition at which the CVVL system operates is higher than the idle speed of the vehicle, which implies that the camshaft speed is $300 \mathrm{rpm}$. It can be concluded that the required torque for the BLDC motor should be more than $0.35 \mathrm{Nm}$.

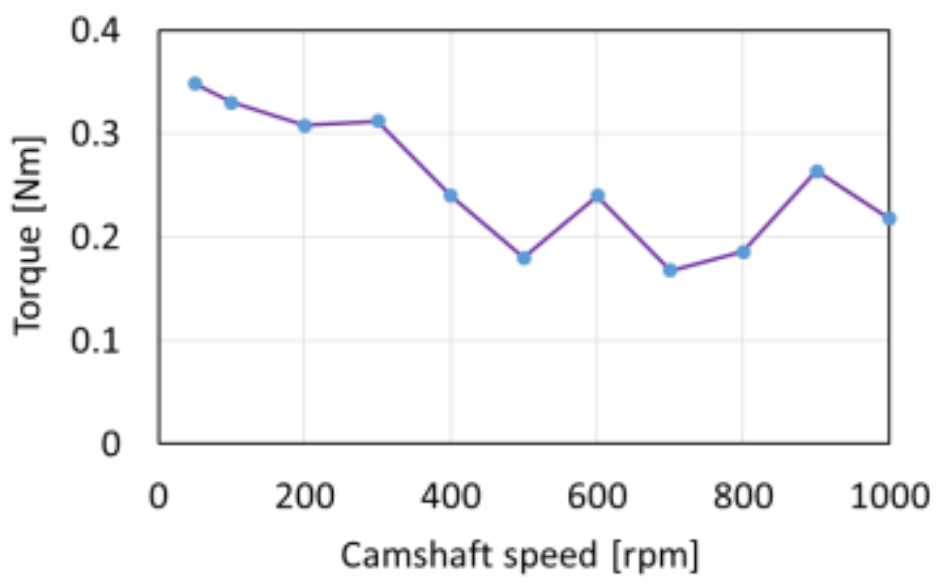

Figure 4. Torque Ripple of the Camshaft

\section{BLDC Motor}

The BLDC motor designed in this study is an IPM-type BLDC motor that uses the $\mathrm{NdFeB}$ magnet. Figure 5 shows the design process of the BLDC motor for driving the CVVL system [15]. First, the BLDC motor design target specification is selected. Mechanical dimensions, such as the outer diameter and inner diameter of the stator and rotor, are calculated by taking into account the ratio of the magnetic and electrical loads. Then, the magnetic flux density of the permanent magnet of the rotor is determined, and the effective magnetic flux per one pole is calculated. Specifications that are the same as the number of turns and the number of revolutions of the stator winding are determined to 
design the BLDC motor. Table 2 shows the specifications of the BLDC motor. The concentrated winding of the stator was wound in 9 slots. The magnet of the rotor had the arrangement of 6 poles. The designed motor was an IPM-type BLDC motor that uses the $\mathrm{NdFeB}$ permanent magnet, which has a high magnetic flux density.

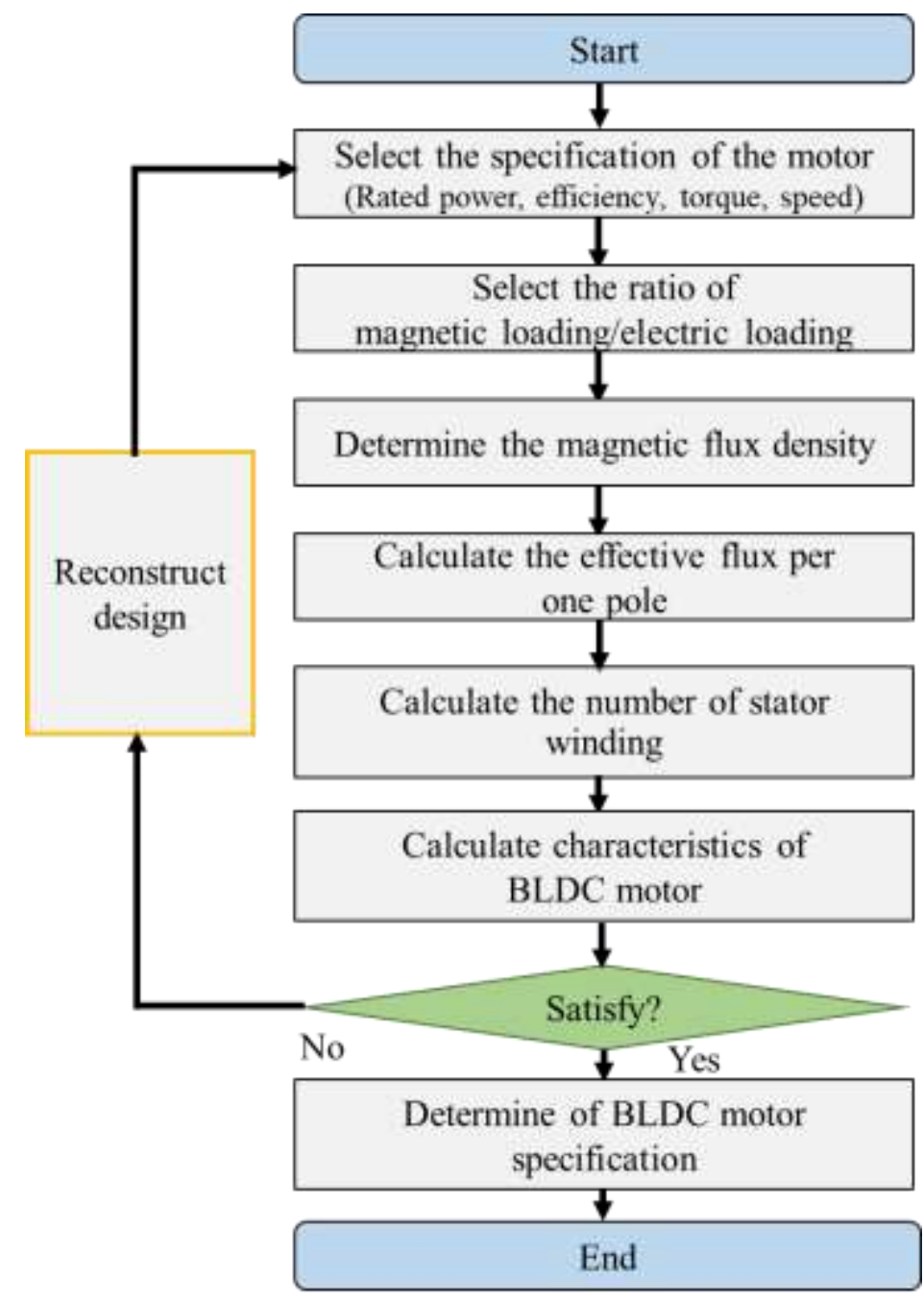

Figure 5. Design Procedure of the BLDC Motor

Table 2. Specifications of the BLDC Motor

\begin{tabular}{|c|c|c|c|}
\hline \multirow{2}{*}{ Stator } & Items & Value & Unit \\
\cline { 2 - 4 } & Number of slots & 24 & - \\
\cline { 2 - 4 } & Outer diameter & 55 & $\mathrm{~mm}$ \\
\hline \multirow{3}{*}{ Rotor } & Inner diameter & 31 & $\mathrm{~mm}$ \\
\hline \multirow{3}{*}{ Rated } & Number of pole & 6 & - \\
\cline { 2 - 4 } & Outer diameter & 30 & $\mathrm{~mm}$ \\
\cline { 2 - 4 } & Inner diameter & 6 & $\mathrm{~mm}$ \\
\cline { 2 - 4 } & Speed & 4000 & $\mathrm{rpm}$ \\
\cline { 2 - 4 } & Output power & 120 & $\mathrm{~W}$ \\
\hline Air gap & Output torque & 0.35 & $\mathrm{Nm}$ \\
\hline Stack & Length & 0.5 & $\mathrm{~mm}$ \\
\hline Magnet & Length & 50 & $\mathrm{~mm}$ \\
\hline & Material & $\mathrm{NdFeB}$ & $(\mathrm{N} 42 \mathrm{SH})$ \\
\hline
\end{tabular}


The assembly and cross-sectional view of the BLDC motor are shown in Figure 5. The BLDC motor assembly consists of a motor part for driving, a sensor part for detecting the position of the rotor, a connector for receiving power and signals from the controller, and a shaft for coupling with the worm gear. The shape of the BLDC motor was designed to improve the torque by reducing the leakage of magnetic flux and the controllability by the low cogging torque characteristic.
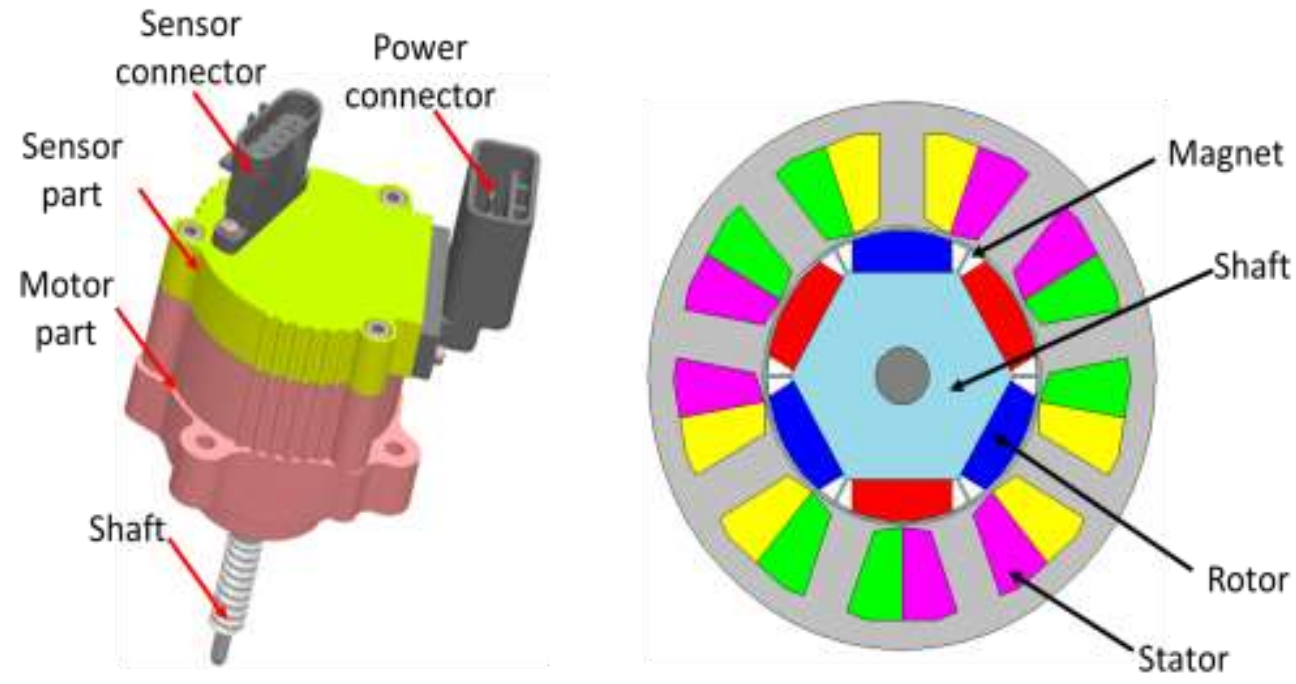

\section{Figure 5. BLDC Motor Assembly and Cross-sectional View of BLDC Motor}

The characteristics of the torque ripple and cogging torque of the BLDC motor were analyzed by $2 \mathrm{D}$ finite element analysis. The torque ripple waveform in Figure 6 operated at rated conditions $(4000 \mathrm{rpm}, 120 \mathrm{~W})$. The average torque was $0.347 \mathrm{Nm}$. The torque characteristics analysis result was similar to the average torque design target specification of $0.35 \mathrm{Nm}$. The characteristics of the cogging torque are shown in Figure 7. The peak-topeak of the cogging torque of the designed model was $0.0327 \mathrm{Nm}$. Therefore, the cogging torque characteristic of the design model was reduced to $9.35 \%$ compared to the rated torque of $0.35 \mathrm{Nm}$.

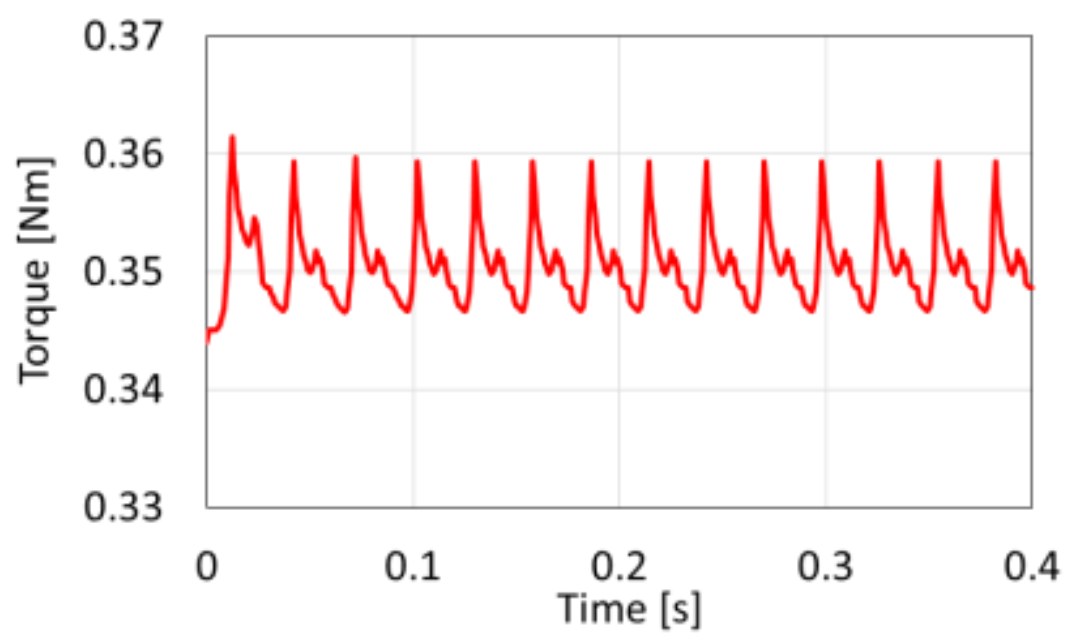

Figure 6. Characteristics of the Torque Ripple (4000 rpm, 120 W) 


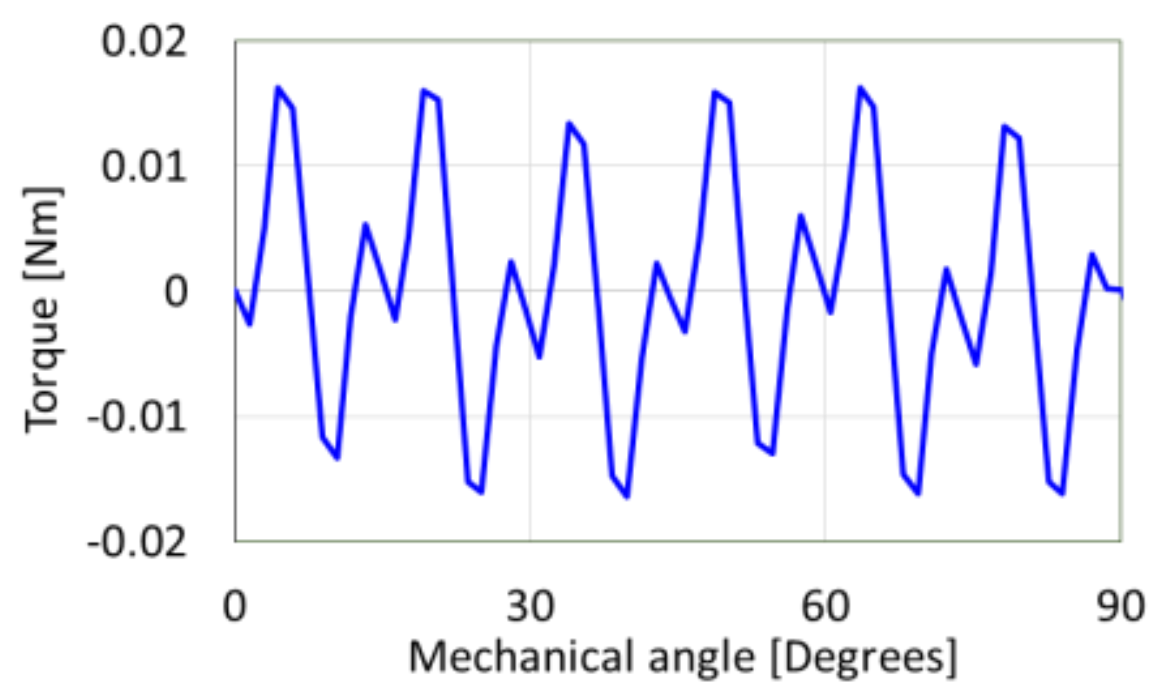

Figure 7. Characteristics of the Cogging Torque

Figure 8 shows a prototype of the BLDC motor assembly and controller. The controller is designed to sense the position of the rotor from the hall sensor of the BLDC and to supply current at the proper timing so that the motor can be driven accurately. Furthermore, because it has a built-in MCU with an internal DSP function, analog / PWM output can be easily generated without any conversion process, and circuit configuration is simple and can be implemented at a relatively low cost.
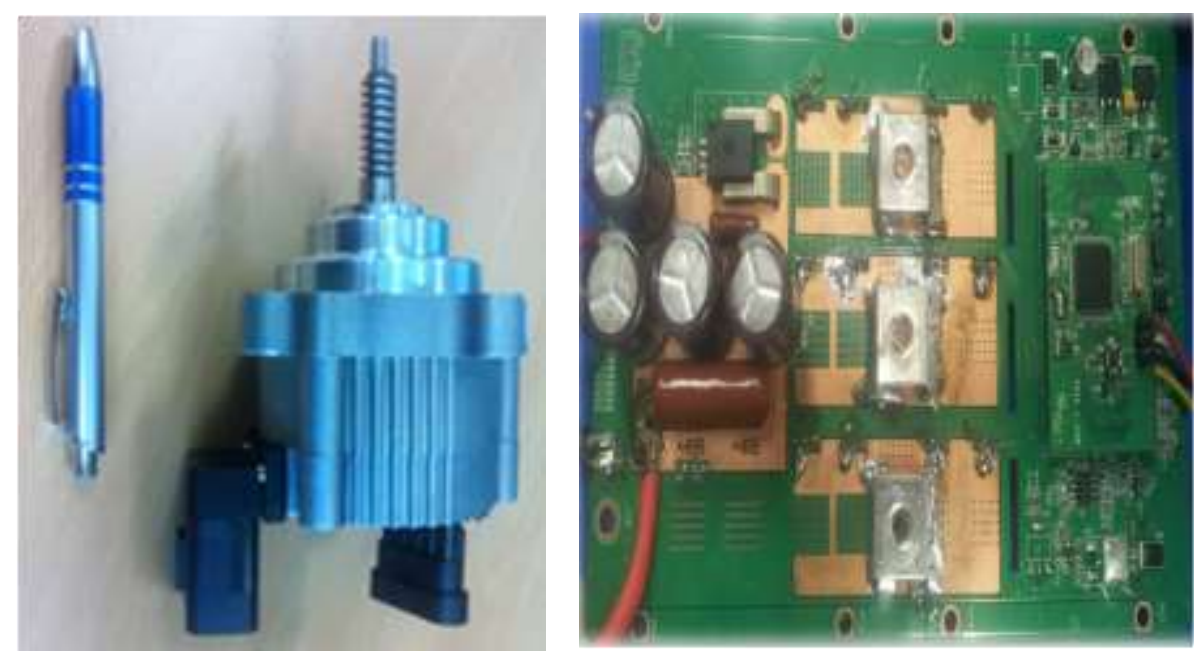

Figure 8. Prototype of BLDC Motor Assembly and Controller

\section{Experiment of CVVL Motor Performance}

BLDC motors designed for CVVL system were mounted on the engine and the performance was tested. Figure 9 shows the implementation of the CVVL monitoring system and shows the operation of the motor while varying the lifting of the intake valve according to the rotation speed of the camshaft. Figure 10 shows the CVVL motor performance tester. The performance tester is similar to the vehicle condition, with engine oil circulating and BLDC motor operation controlling the opening and closing of the intake valve. 


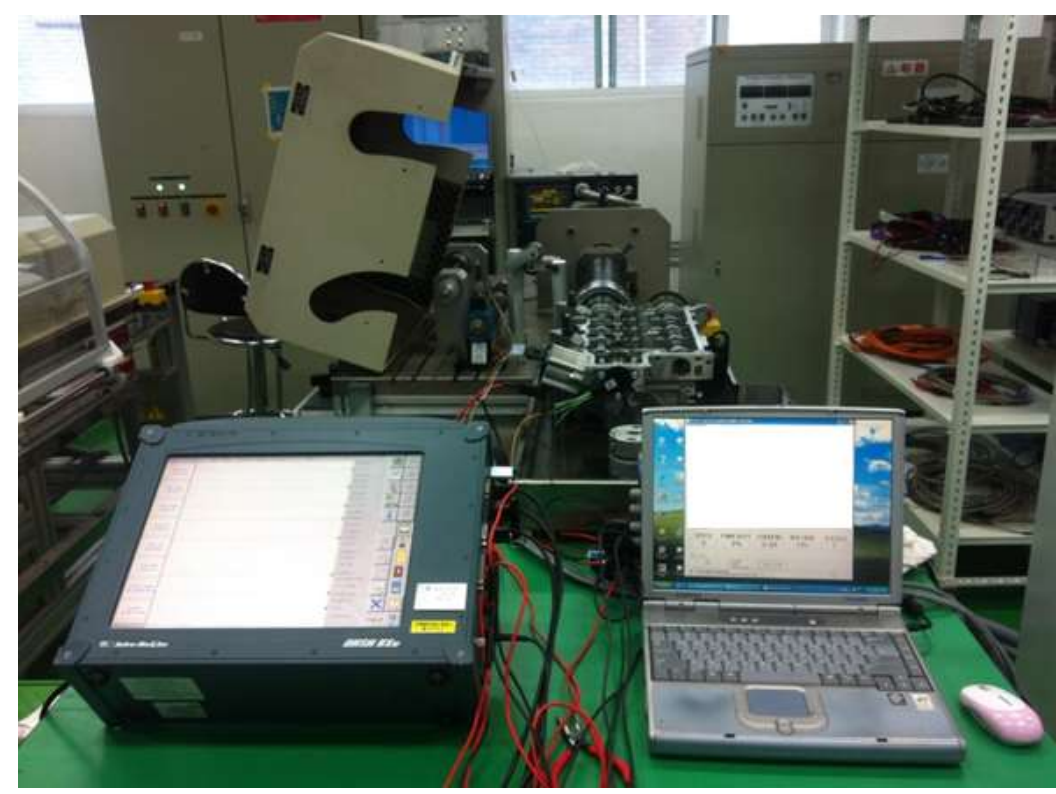

Figure 9. Implementation of the CVVL Monitoring System

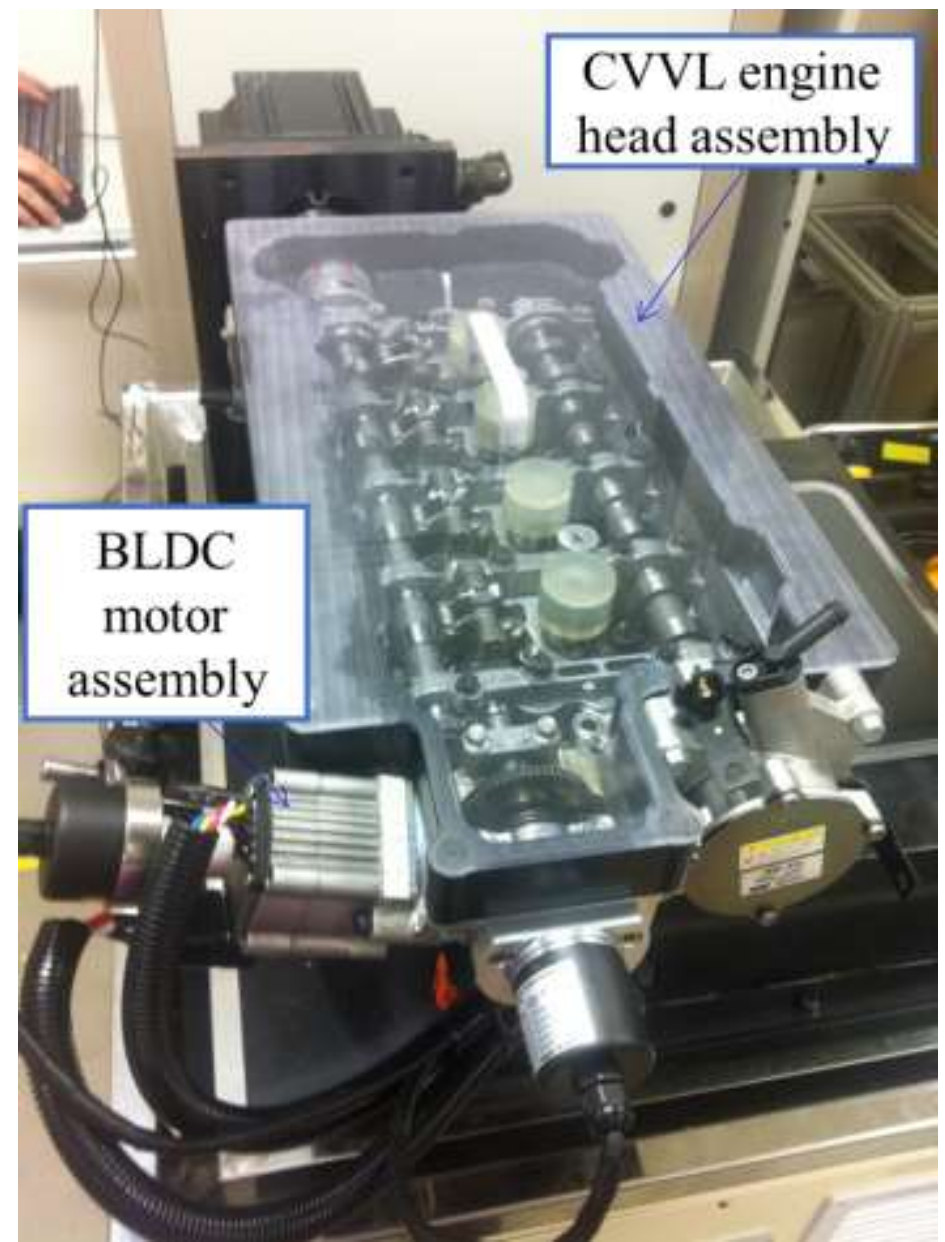

Figure 10. CVVL Motor Performance Tester (Engine Condition Simulation)

Table 3 shows the torque characteristics of the camshaft using the CVVL motor performance tester. Figure 11 compares the torque ripple value of the camshaft with the rotation speed. The maximum torque (Tmax), minimum torque (Tmin), torque ripple 
(Tpp), and average torque (Tavg) of the camshaft were sequentially changed by varying the crankshaft rotation speed sequentially from $50 \mathrm{rpm}$ to $1000 \mathrm{rpm}$. Although the torque of the BLDC motor is required for variable valve lifting at the low speed of the camshaft and CVVL engine, the torque required by the motor is lowered when the camshaft speed is above $500 \mathrm{rpm}$. Therefore, it is confirmed that the characteristics of the BLDC motor designed in this study are suitable, and the CVVL system can be driven.

Table 3. Torque Characteristics of the Camshaft (by the CVVL Motor Performance Tester)

\begin{tabular}{|c|c|c|c|c|}
\hline Speed[rpm] & Tmax $[\mathbf{N m}]$ & Tmin[Nm] & Tpp[Nm] & Tavg[Nm] \\
\hline $\mathbf{5 0}$ & 0.222 & -0.082 & 0.304 & 0.0611 \\
\hline $\mathbf{1 0 0}$ & 0.211 & -0.077 & 0.288 & 0.0165 \\
\hline $\mathbf{2 0 0}$ & 0.215 & -0.061 & 0.276 & 0.0168 \\
\hline $\mathbf{3 0 0}$ & 0.205 & -0.058 & 0.263 & 0.0454 \\
\hline $\mathbf{4 0 0}$ & 0.145 & -0.075 & 0.22 & 0.0455 \\
\hline $\mathbf{5 0 0}$ & 0.168 & -0.015 & 0.183 & 0.0399 \\
\hline $\mathbf{6 0 0}$ & 0.179 & -0.035 & 0.214 & 0.0470 \\
\hline $\mathbf{7 0 0}$ & 0.113 & -0.023 & 0.136 & 0.0511 \\
\hline $\mathbf{8 0 0}$ & 0.145 & -0.042 & 0.187 & 0.0465 \\
\hline $\mathbf{9 0 0}$ & 0.121 & -0.071 & 0.192 & 0.0528 \\
\hline $\mathbf{1 0 0 0}$ & 0.135 & -0.006 & 0.141 & 0.0599 \\
\hline
\end{tabular}

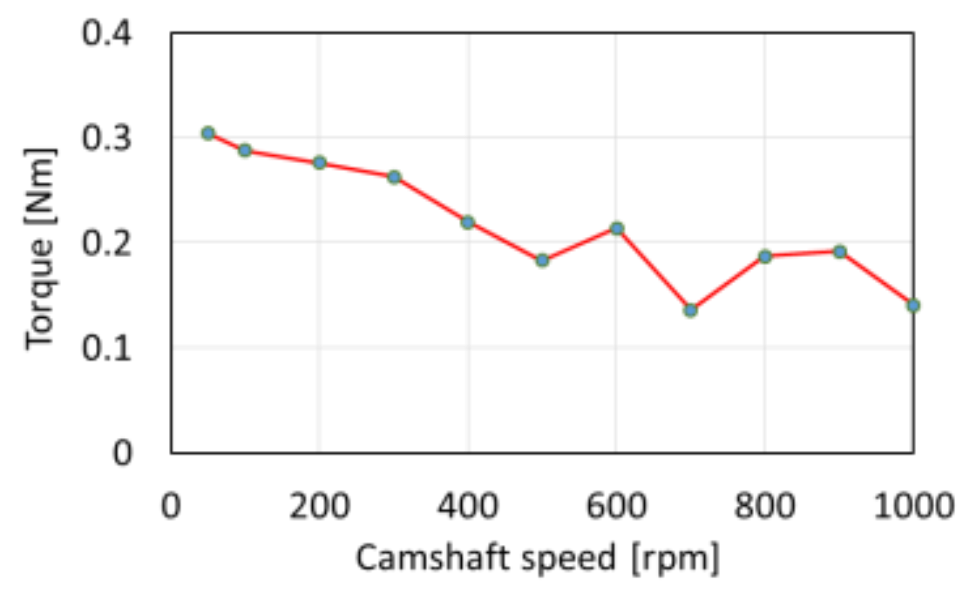

Figure 11. Torque Ripple of the Camshaft (by the CVVL Motor Performance
Tester)

\section{Conclusion}

In this study, a BLDC motor assembly, which is a key component for the development of the CVVL system, was designed and prototypes were produced. Furthermore, a performance tester was constructed to evaluate the performance of the prototype. The torque required from the camshaft was measured to estimate the capacity of the BLDC motor used in the CVVL system. To improve the controllability and durability of the BLDC motor, an IPM-type rare earth permanent magnet was used. It was designed to improve the torque characteristics and reduce the cogging torque of the motor. The rated torque of the BLDC motor was $0.35 \mathrm{Nm}$, and the cogging torque was $9.35 \%$ of the rated torque. The designed BLDC motor assembly was combined with the CVVL engine head assembly to verify the operability of the CVVL system. In the case of gasoline direct injection (GDI), development of a CVVL system is necessary to control the flow in the 
cylinder according to engine operating conditions. The application of a CVVL system enables precise control and stable operation of GDI. Currently, the application of a CVVL system is focused only on a gasoline engine, but it is expected to be applied to diesel engines, if the technology is universalized.

\section{Acknowledgments}

This study is a revised and expanded version of a paper entitled [A Study on Design of BLDC Motor for Continuous Variable Valve Lift] presented at [7th International Conference on Next Generation Computer and Information Technology (NGCIT) 2018, Hokkaido, Japan, 23-26 Aug, 2018]. This paper was supported by the National Research Foundation of Korea (NRF) grant funded by the Korea government (MSIT) (No. 2017R1C1B5075525).

\section{References}

[1] N. Latha and K. Sathish, "Retrofit adaptation of exhaust sensors for Euro 6 Emission standard", International Journal of Innovative Research in Science, Engineering and Technology, vol. 5, issue. 5, (2016), pp. 7782-7785.

[2] A. Moody and J. Tate, "In Service CO2 and NOX Emissions of Euro 6/VI Cars, Light- and Heavydutygoods Vehicles in Real London driving: Taking the Road into the Laboratory", Journal of Earth Sciences and Geotechnical Engineering, vol. 7, no. 1, (2017), pp. 51-62.

[3] F. Berthold, A. Ravey, B. Blunier, D. Bouquain, S. Williamson and A. Miraoui, "Design and Development of a Smart Control Strategy for Plug-In Hybrid Vehicles Including Vehicle-to-Home Functionality", IEEE Transactions on Transportation Electrification, vol. 1, no. 2, (2015), pp. 168-177.

[4] J. Ma, G. G. Zhu and H. Schock, "Adaptive Control of a Pneumatic Valve Actuator for an Internal Combustion Engine", IEEE Transactions on Control Systems Technology, vol. 19, no. 4, (2011), pp. 730-743.

[5] S. Potul, R. Nachnolkar and S. Bhave, "Analysis of Change in Intake Manifold Length and Development of Variable Intake System”, International Journal of Scientific \& Technology Research, vol. 3, no. 5, (2014), pp. 223-228.

[6] A. A. Sabaruddin, S. Wiriadidjaja, A. S. M. Rafie, F. I. Romli and H. Djojodihardjo, "Engine Optimization by using Variable Valve Timing System at Low Engine Revolution", ARPN Journal of Engineering and Applied Sciences, vol. 10, no. 20, (2015), pp. 9730-9735.

[7] S. H. Khudhur, A. M. Saleh, and M. T. Chaichan, "The Effect of Variable Valve Timing on SIE Performance and Emissions”, International Journal of Scientific \& Engineering Research, vol. 6, no. 8, (2015), pp. 173-179.

[8] P. K. Wong, L. M. Tam and K. Li, "Modeling and simulation of a dual-mode electrohydraulic fully variable valve train for four-stroke engines", International Journal of Automotive Technology, vol. 9, no. 5, (2008), pp.509-521.

[9] J. R. Liu, B. Jin, Y. J. Xie, Y. Chen and Z. T. Weng, "Research on the electro-hydraulic variable valve actuation system based on a three-way proportional reducing valve", International Journal of Automotive Technology, vol. 10, no. 1, (2009), pp. 27-36.

[10] J. D. Chen, "Dynamic Simulation and Experiments of a Novel Variable Valve Timing System", International Journal of Multimedia and Ubiquitous Engineering, vol. 9, no. 7, (2014), pp. 383-394.

[11] H. Liao, M. J. Roelle, J. Chen, S. Park and J. C. Gerdes, "Implementation and Analysis of a Repetitive Controller for an Electro-Hydraulic Engine Valve System", IEEE Transactions on Control Systems Technology, vol. 19, no. 5, (2011), pp. 1102-1113.

[12] J. Zhao and R. J. Seethaler, "A Fully Flexible Valve Actuation System for Internal Combustion Engines", IEEE/ASME Transactions on Mechatronics, vol. 16, no. 2, (2011), pp. 361-370.

[13] Y. Yang, J. Liu, D. Ye, Y. Chen and P. Lu, "Multiobjective Optimal Design and Soft Landing Control of an Electromagnetic Valve Actuator for a Camless Engine", IEEE/ASME Transactions on Mechatronics, vol. 18, no. 3, (2013), pp. 963-972.

[14] M. D. Bernardo, A. D. Gaeta, C. I. H. Velasco and S. Santini, "Energy-Based Key-On Control of a Double Magnet Electromechanical Valve Actuator", IEEE Transactions on Control Systems Technology, vol. 20, no. 5, (2012), pp. 1133-1145.

[15] S. W. Baek, "A Study on Design of BLDC Motor for Continuous Variable Valve Lift", Proceedings of the 7th International Conference on Next Generation Computer and Information Technology, Hokkaido, Japan, (2018) Aug 23-26. 


\section{Author}

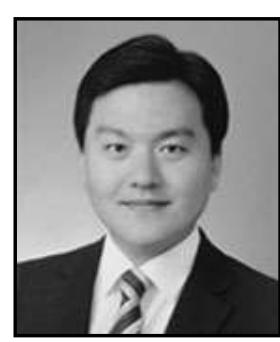

Soo-Whang Baek, received the Ph.D. degree from the Department of Electronic, Electrical, Control and Instrumentation Engineering, Hanyang University, Korea, in 2012. From 2012 to 2016, he was a senior Engineer in the R\&D Center, Hyundai KEFICO, Korea, where he was engaged in research on motor drive systems for automotive. Since 2016, he has been a Professor at the Department of Automotive, Honam University, Korea. His current research interests include HEV, $\mathrm{EV}$, design and control of electric machine for automotive. 